\title{
AFFORESTATION OF RURAL LAND IN GREECE: A MULTINOMIAL LOGISTIC REGRESSION ANALYSIS OF DRIVING FACTORS
}

\author{
O. CHRISTOPOULOU \& D. MINETOS \\ Department of Planning and Regional Development, University of Thessaly, Volos, Greece.
}

\begin{abstract}
This article deals with the importance of European Agricultural Fund for Rural Development through the implementation of afforestation schemes in rural communities. The main aim of the article is to investigate the spatial patterns of afforestation in Greece, the driving factors behind these patterns as well as the degree of the success of the EU policy for forest expansion through afforestation of arable land. Therefore, the focus is on providing a concrete appraisal regarding the contribution of EU 2080/92 and 1257/99 Regulations to the improvement of regional forest status by means of increasing forest areas and improving the local people's standard of living. The study area covers the entire Greek territory which consists of 51 administrative prefectures. Methodologically speaking, the empirical analysis is based on a multinomial logistic regression model targeted at providing a thorough understanding of the major driving factors that influence rural communities' response to the regulations. The environmental importance of arable land afforestation is highlighted as well as the extent to which the regulations has met the initial expectations.

Keywords: afforestation, EU Regulation 2080/92, EU Regulation 1257/99, forest resources, Greece, multifunctional agriculture, multinomial logistic regression, rural development, rural land, spatial analysis.
\end{abstract}

\section{INTRODUCTION}

In recent decades, land use patterns have undergone tremendous transformations of such a magnitude that have attracted considerable attention within the scientific community. At present, an international multidisciplinary debate is in progress among scientists, experts, policy makers, non-governmental organisations and various economic and institutional players with some interest at or involvement in land use allocation. In some respects, this is due to the fact that the magnitude and pace of land change have risen considerably, affecting almost all fundamental components of the system created from both natural and anthropogenic communities. The most affected uses of land seem to be agricultural and forest uses. Rural areas in the EU make up $80 \%$ of the territory and have approximately $25 \%$ of the population. These areas have undergone major adjustments resulting from agricultural policies and other driving forces such as policy decisions about tourism, transportation networks and forestry.

Implications have been great and pressuring, especially those concerning forests and soil, ranging from biotic diversity threats, desertification and forest and open land 'squeeze' to increased vulnerability to human settlements as well as local water and food shortage. Therefore, there is a pressuring need for designing and applying integrated, sustainable and realistic forest policies tightly connected to the requirements for improving the local people's quality of life. The declining economic viability of rural areas not only in Greece but also in other Mediterranean countries has forced the decision makers to develop policies targeted at delivering support to the rural communities to invert the current situation. Multifunctional forestry is perceived as a means of rural development. It is also considered to be an important vehicle for diversifying the countryside through the restoration of existing woodlands and the establishment of new forests on suitable land including former agricultural land $[1,2]$. In this way, it is possible to strengthen the livelihood base and the quality of life in rural areas.

Afforestation of marginal agricultural land through the EU Regulations 2080/92 and 1257/99 is a Common Agricultural Policy (CAP) target focused on (a) decreasing agricultural goods production

(C) 2009 WIT Press, www.witpress.com

ISSN: 1743-7601 (paper format), ISSN: 1743-761X (online), http://journals.witpress.com DOI: $10.2495 /$ SDP-V4-N3-238-257 
and, therefore, lowering the current level of financial support to the agricultural sector through subsidies (b) encouraging development of forestry activities in rural areas in order to improve the livelihood and standards of living in the countryside and (c) contributing to climate change mitigation by dealing with carbon sequestration as well as other anthropogenic emissions of green house gases.

However, the expansion of forest areas through policy initiatives not only generate environmental and socio-economic benefits for local communities but also involves some costs deriving from the fact that there are fewer opportunities for alternative land uses. Nevertheless, it can be said that agricultural surpluses in Europe and marginal agricultural land especially in the Mediterranean increase the scope for designing and carrying out afforestation policies with little negative effect on agriculture or on other alternative land uses. Since 2000, forestry measures have been grouped in two categories of action: (a) afforestation and (b) other forestry measures. All have been financed by rural development funds. Planned EU spending on forestry for the period 2000-2006 is $€ 4.7$ billion, half for afforestation of agricultural land and half for other forestry measures.

The present analysis attempts to provide useful insights concerning the evaluation of afforestation policies of arable land in Greece. This information on the determinants of rural communities' response to afforestation initiatives could be useful for improving the effectiveness of afforestation schemes. The originality of the present research lies on the fact that there are not relevant analyses at the regional level in Greece. There are only a limited number of scientific papers investigating land use changes in Greece due to the EU 2080/92 regulation [3,4] and they are mostly at the level of individual farmers using primary data from questionnaire surveys or similar sources. An overview of the established spatial patterns of afforestation as well as the structural elements of these patterns can become a supportive tool for policy priorities identification in the field of regional afforestation planning.

The remainder of the article is organised as follows: Section 2 describes and discusses the context of Greek forest policy in the last few decades. It also deals with the European CAP and in particular, the policy aspects concerning afforestation programmes in member states. Section 3 presents the study area, the variables used in the empirical analysis, data sources as well as the multinomial logistic regression model of afforestation. Following, Section 4 reports model fitting information and the results of the analysis. Section 5 concludes by drawing some wider implications on the implementation of EU afforestation policies in Greece.

\section{FOREST POLICY IN GREECE AND THE EU}

In Greece, the central body for state administration in the forestry sector is the Forestry Section of the Ministry of Rural Development and Food, which deals with strategy and policy design, policy implementation issues as well as the forestry legal framework. Strategies designed within the Forestry Section are forwarded to the Greek Parliament for approval and sequentially they are pursued through implementation mechanisms at the regional and local levels. Institutionally speaking, forests and forest land areas have a strong degree of protection under the Hellenic Constitutional principal (articles 24 and 117, 1975/86/00) 'forest use change only for the public interest and only in cases in which the public interest cannot be accommodated for by alternative means that do not include forest land use change'. However, inefficiencies and failures in the administrative and managerial levels have resulted in severe forest degradation mostly in near-urban areas through the mechanism of forest fires and the subsequent building of burnt areas.

The constitutional prohibition regarding changes in forest land cover - unless in the public interest - does not seem to have been fulfilled despite the various legislative attempts to protect forest land uses. The Greek Forest Act of 1979 (Law 998/79) forms the basis of the national forest policy, maintaining two fundamental principles: increased protection of forests characteristics and sustainable use of forest resources in that all forest functions must be protected and if possible enhanced including 
biological diversity, recreation and erosion mitigation functions. Provisions are also made about additional significant management issues such as demarcation of forest areas by a cadastral system, reforestation procedures and national forest research and management funding.

Prior to the 1975 Constitution, forest activities were initially carried out under the provisions of the 1929 Forest Act. Economic exploitation of forest resources was the priority of the state's efforts, reflecting the prevailing social, cultural and economic conditions at that period. The first substantial amendment to the above law was made in 1969 with the introduction of the controversial Forest Act numbered 86/1969. It has been argued that under the 1969 act, degradation of forests increased considerably as some of the act's provisions accounted for the construction of buildings and hotels within forest areas.

After the 1975 Constitution and the 1979 Forest Act, there were some attempts to amend the forestry legal framework. Of some relevant importance are two such efforts. The first refers to the Pastoral Act of 1987 (Act 1734/1987). Among others, the act attempted to establish a distinction between tree forests and other forest land areas (shrubs, bushland, etc.) with the latter been characterised as pastures. This law was inactivated by a judicial verdict. Finally, in 2003 a new forest act (Act 3208/2003) which raised substantial political criticism deriving mostly from environmental institutions and non-governmental organisations was introduced. This time, the hot spot was the operational definition of the concept 'forest'. The new definition proposed by the act reduced the level of protection of certain floral communities such as Mediterranean shrubs. A judicial process is again under way as to what extent the act is in line with the Hellenic constitutional requirements as well as EU legislation.

In sum, it can be said that both the administrative structure and the legislative frameworks remain, to a large extent, bureaucratic. Registration of forest land by the Greek cadastral system is still in its initial stage. Reforestation activities are inadequate and in some cases inappropriate (e.g. poor choices of vegetation species to be planted by the authorities in charge) and peri-urban forests are subject to forest fires and urban sprawl. The status of forest land areas in Greece in relation to property right is presented in Table 1 . In particular, $65.5 \%$ of forest land belongs to the state and only $8 \%$ is under private ownership. As regards shrubland, where soil is of low fertility and arid conditions prevail, about $83 \%$ is state property and $5 \%$ belong to private owners. Although the percentage of privately owned forest land is relatively low, there is considerable pressure by private owners to relax the degree of protection of these areas in order to become developable. This is particularly evident in coastal and insular areas where the demand for new land for tourism development purposes is high.

At the EU level, despite the importance of forest sector, the community has not placed forest policy among the commonly designed and agreed policies [5]. It was until 1998 that the European

Table 1: Forest resources in Greece.

\begin{tabular}{lcrcrcr}
\hline Ownership & $\begin{array}{c}\text { Forest } \\
(1000 \mathrm{ha})\end{array}$ & $\%$ & $\begin{array}{c}\text { Shrubs } \\
(1000 \mathrm{ha})\end{array}$ & $\%$ & $\begin{array}{c}\text { Total of forest and } \\
\text { forest land (1000 ha })\end{array}$ & $\%$ \\
\hline State & 2,200 & 65.5 & 2,626 & 83.3 & 4,826 & 74.1 \\
Municipalities & 403 & 12.0 & 183 & 5.8 & 587 & 9.0 \\
Private bodies & 269 & 8.0 & 154 & 4.9 & 423 & 6.5 \\
Other & 487 & 14.5 & 190 & 6.0 & 677 & 10.4 \\
Total & 3,359 & 100.0 & 3,154 & 100.0 & 6,513 & 100.0 \\
\hline
\end{tabular}


Council adopted a Resolution on Forestry Strategy to act as the new framework for EU forest activities. Over the years, the European forest policy started to emerge mostly as part of other related policies [6] such as the CAP (afforestation of agricultural land, energy crops, agricultural code of good practice for the prevention of water pollution), product policy (eco-labelling of forest products) and environment policy (protection of biodiversity, green house effect measures, etc.). Gradually, the EU recognised that converting non-forest land to forests could have a number of beneficial effects not least by increasing the diversity of flora and fauna, having a multifunctional developmental role as well as acting as a carbon dioxide sink. Sustainable development would require the sensible use and preservation of forest resources through improved management techniques, strategic planning and monitoring.

Hence, the EEC Regulation 2080/92 set up a community aid scheme for rural areas through the alternative utilisation of agricultural land by means of afforestation and the development of forestrelated activities in farms. The costs of afforestation or woodland improvement was supported as much as up to $100 \%$ of the project work costs including land preparation, plant purchase and planting. The contribution covers losses of income resulting from afforestation of agricultural land. For the implementation of EEC Regulation 2080/92, regional programmes were set up which were subsequently approved by the EU. The comparative performance of the programme for the $12 \mathrm{EU}$ countries for the period from 1993 to 1997 is presented in Fig. 1.

In Greece, the implementation of the Regulation 2080/92 from 1993 to 2001 resulted in the establishment of 35,836 ha of forest plantations. From 1999, a new Regulation (EU 1257/99) which targeted the improvement of regional forest status by means of increasing forest areas and improving the local people's standard of living has been introduced. However, there are significant differences regarding the participation of the individual areas in the afforestation scheme at the regional level. A close consideration of the spatial distribution of funding reveals that the participation in afforestation of areas in which there is a strong need to improve and expand their forest resources is poor. The likely driving factor of the observed regional differentiations is considered in the following sections.

\section{STUDY AREA AND METHODOLOGY}

\subsection{Study area}

Administratively speaking, Greece is divided into 13 regions (NUTS II), which consist of 51 prefectures (Fig. 2). The total area of the country is proximately $131,957 \mathrm{~km}^{2}$ consisting of the mainland part of the country as well as some 3,000 habited and inhabited islands. The coastline is extensive and stretches for approximately $16,500 \mathrm{~km}$, representing about $25 \%$ of the EU coastline. The country's population is approximately 11 million people with $72.8 \%$ staying in urban areas and the remaining $27.2 \%$ being rural population. The percentage of the population in mountainous areas is $9.2 \%$, whereas in semi-mountainous and urban areas the figures are $21.8 \%$ and $69.0 \%$, respectively. Agriculture and pastoral uses cover $49.5 \%$ of country's surface, forests, shrub and bare land cover $47.2 \%$, inland water covers $1.3 \%$ and urban and other artificial surfaces cover $2.0 \%$ [8].

There are about 5,000 floral species recorded in Greece among which about 750 are endemic to the country. Plant communities include forests of broadleaf evergreen trees, oak woodlands, sclerophyllic bushes of maquis and garrigue. On most of the insular areas, maquis communities may be the climax. However, in the mainland parts of the country, this type of vegetation has usually been the outcome of forest dislocation and overexploitation. The country has a Mediterranean type of climate with high temperatures and very low rainfalls in the summer. As regards the regional administrative structure of forest sector, there are 50 forest offices through which the afforestation information became available. 


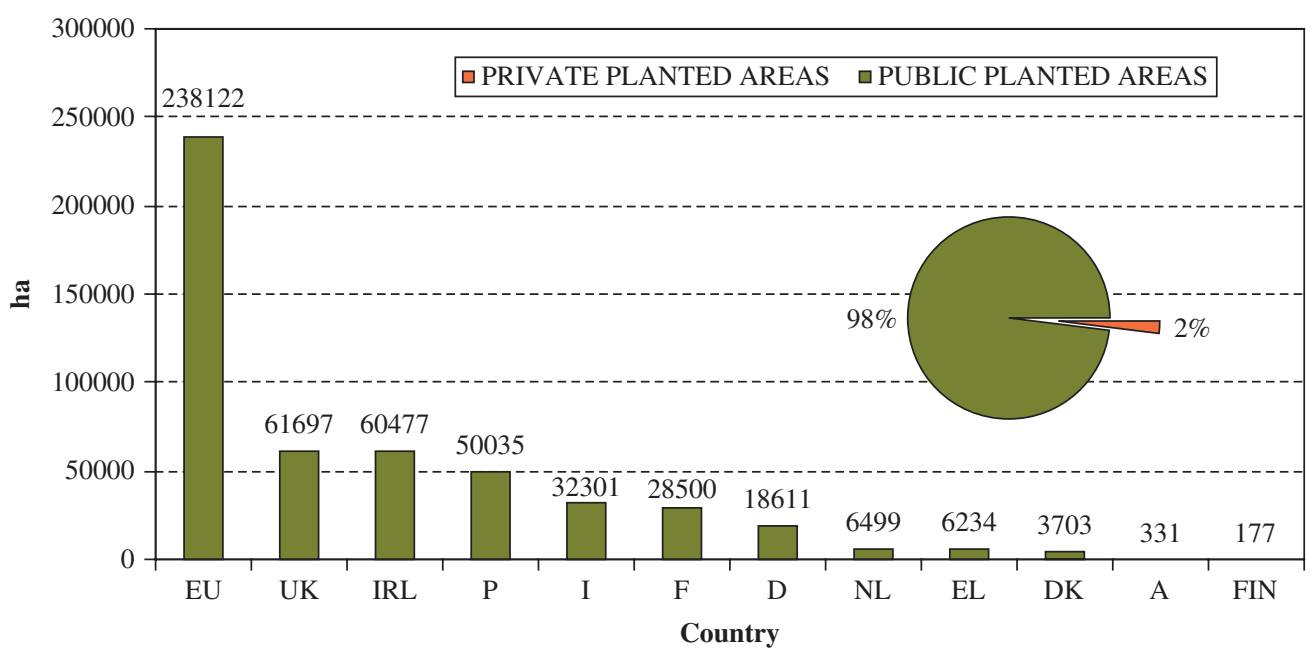

Figure 1: 12 EU: New forest planted area under EU Regulation 2080/92 in the period 1993-1997. Source: European Union [7], $\operatorname{COM}(97) 630$ final.

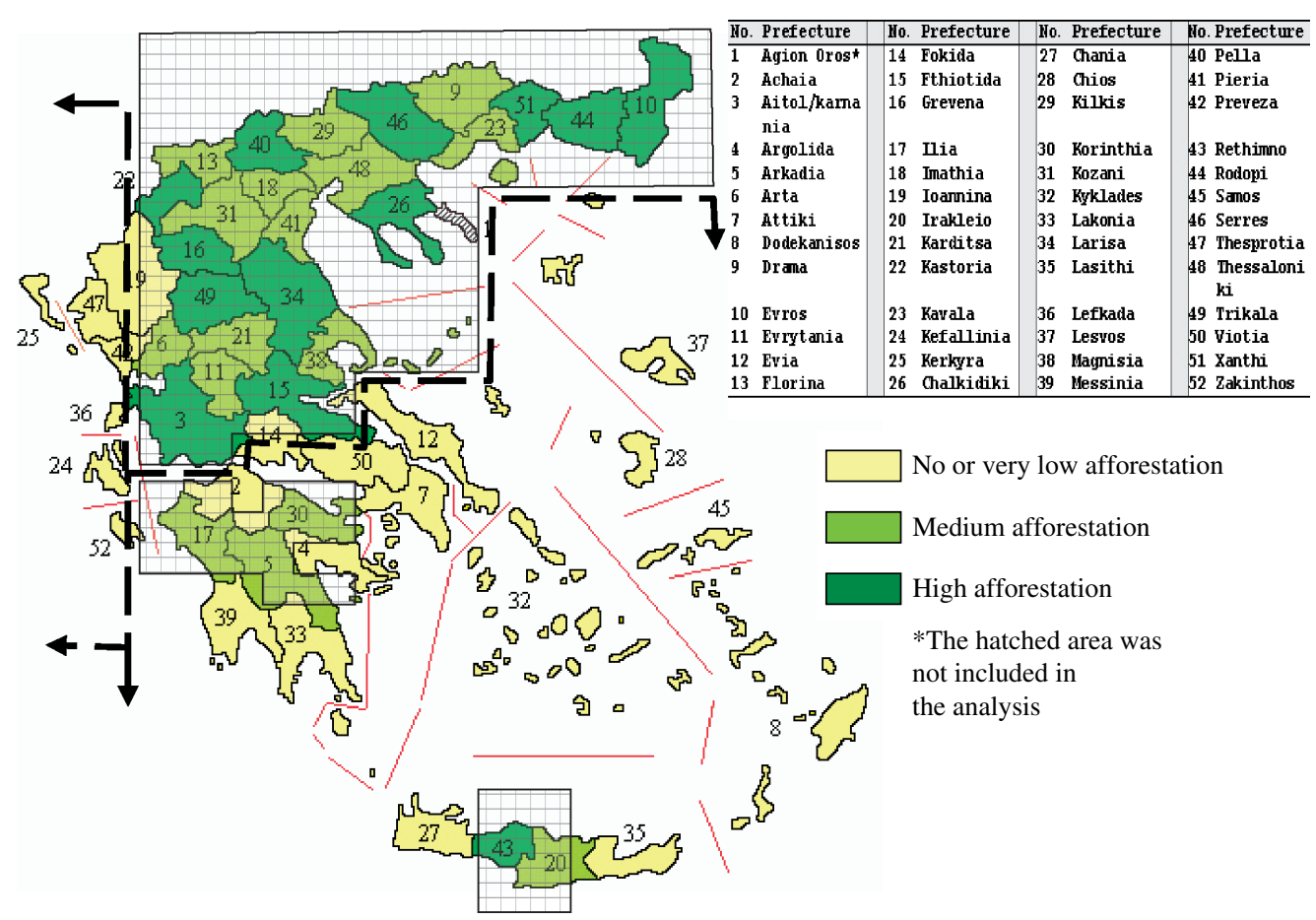

Figure 2: Spatial distribution of afforestation subsidies in Greece through the implementation of EU regulations 2080/92 and 1257/99 for the period 2002-2005. 


\subsection{Selection of variables}

Data for estimating the regional response to the provisions of the regulations were derived from the Ministry of Rural Development and Food. The data depict the total amount of subsidies (National and EU shares) for the period from 2002 to 2005 in the NUTS III level. The total funding through the regulations during that period is a representative indicator of the expressed demand for entering into the programme for the whole period of the regulations' application. This is because shortly after the lunching of the first regulation in 1992, there was a relatively long period of low response due to insufficient dissemination of information about the programme and the lack of experience of the local forest offices to promote the initiative and stimulate demand. Therefore, the established patterns of farmers' response to the initiative in the early 2000 provide a more representative picture of the actual influence of the programme.

The original data for this variable were transformed in order to construct broad spatial categories of afforestation and subsequently to investigate the relative response to the programme against a diverse group of continuous and categorical variables, which we considered as the major driving factors of afforestation. Hence, the prefectures were classified into three categories according to the total funding they received through the regulations during the study period. The categories are as follows:

- Category 1: Prefectures with no response or very low response to the regulations $(€ 0-100,000)$

- Category 2: Prefectures with medium response to the regulations (€100,000-1,000,000)

- Category 3: Prefectures with high response to the regulations $(€ 1,000,000+)$

The patterns and spatial distribution of subsidies are shown in Fig. 2 and Table 2. As we can observe, there are distinctive spatial differentiations among the spatial units. In particular, most of the insular prefectures of the Aegean and Ionian Seas did not respond to the afforestation initiative at all. Generally speaking, the great majority of the west, east and south parts of the country, despite being eligible for participating in the provisions of the regulations, did not present sufficient interest in these forestry support measures. Considerable interest was stimulated at the central and north parts of the country. The prefectures of Evros, Larissa, Pella, Trikala and Grevena were the leading ones in terms of payments for afforestation.

The observed spatial distribution of afforestation payments raises a number of issues relevant to the application of the regulation. Firstly, there is a question about the policy context for afforestation and its ability to respond to regional differentiations in critical economic, societal and environmental issues such as regional structural economic differences, human capital particularities, climate variability and

Table 2: Total afforestation subsidies.

\begin{tabular}{lccc}
\hline $\begin{array}{l}\text { Prefectures of } \\
\text { highest values }\end{array}$ & Value & $\begin{array}{l}\text { Prefectures of } \\
\text { lowest values }\end{array}$ & Value \\
\hline Evros & $10,803,503$ & Samos & 0.00 \\
Larissa & $7,251,167$ & Lesvos & 0.00 \\
Pella & $3,768,280$ & Kyklades & 0.00 \\
Trikala & $3,237,315$ & Dodekanissos & 0.00 \\
Grevena & $2,636,378$ & Lefkada & $0.00^{\mathrm{a}}$ \\
\hline
\end{tabular}

${ }^{a}$ Only a partial list of cases with the value 0.00 are shown in the table of lower extremes. 
floral heterogeneity. Secondly, from an environmental point of view, the actual results delivered by the programme (soil erosion control, biodiversity enhancement, etc.) seem questionable because the major part of the country of low forest cover did not take advantage of the provisions to increase their forestland. Much of the demand for changing the use of agricultural land to forestland was derived from the areas with extensive forest resources. Finally, in the case of Greece, these forestry measures seem that they were not integrated with broader issues like the prevention of natural hazards and the improvement in economic welfare of handicap communities. The national strategy, if any, did not establish priorities and programmes to direct findings in certain places within the eligible prefectures. The dispersion and lack of spatial relevance of individual cases had a negative impact on the effectiveness of actions. Therefore, the need for achieving a spatially explicit, critical mass of actions in certain areas has not been fulfilled. In this respect, any future revision of the forest strategy may need to reflect these issues. Likely changes to be introduced to the structure and programming of funds will require information about complex issues as well as monitoring and evaluation of the effectiveness of rural afforestation actions.

\subsubsection{Afforestation payments}

For the purpose of the current analysis, we consider the total payments per prefecture as the dependent variable. The relevant data were acquired by the Ministry of Rural Development and Food and cover the period from 2002 to 2005 . Because some statistical procedures require that data come from a normal population, we produced a group of plots that we used to look for deviations from normality. In Fig. 3, the normal quantile plot (Q-Q plot) suggests that the values of the variable are not normally distributed. If the data came from a normal distribution, all the points should have been clustered around the straight line. The histogram and stem and leaf plot suggests that there is a peak on the left-hand side of the distribution and a very long tail to right. There are at least five extreme cases that make the distribution particularly asymmetric.

Finally, the box plot in Fig. 3 shows that there is an intense accumulation towards zero values pushing the median to the left side of the box. The whiskers that extend from the right side of the box represent the largest values that are outliers but not extreme cases. Therefore, there are three broad types of spatial units: (a) the prefectures with little response to the afforestation programme that accumulate around the median, (b) the prefectures with medium response that are situated to the right part of the box and (c) the prefectures with high response to the programme that lie outside the box to the right. These characteristics of the dependent variable suggest that the use of a linear regression model might not be appropriate.

\subsubsection{The independent variables}

The purpose of this paper is to seek likely relationships between the magnitude of afforestation payments and a set of selective economic, social and environmental characteristics of the regional units. Therefore, the approach is to combine the observed response to the afforestation programme and some important regional characteristics into an explanatory model in order to account for spatial variations. The factors used in the empirical analysis and the relative hypotheses are presented underneath. In particular, we choose:

- Specialisation in the primary sector: The share of the primary sector of economy in the total production in each prefecture. We expect that the prefectures whose economies are based on the primary sectors of production would have higher response rates to the regulation compared to the remaining prefectures and therefore they would experience increased demand for afforestation payments. The existence of a large and diverse primary sector in the local economy might result in the accumulation of experience in the sector and the establishment of some local tradition for participating in European Agricultural 
Total Afforestation Subsidies Stem-and-Leaf Plot

Frequency Stem \& Leaf

$\begin{array}{ll}31.00 & 0.0000000000000000000000111123334 \\ 7.00 & 0.5788899 \\ 4.00 & 1.0134 \\ 3.00 & 1.557 \\ 1.00 & 2.3 \\ 5.00 \text { Extremes }(\geq 2636378)\end{array}$

Stem width: 1000000

Each leaf: 1 case(s)

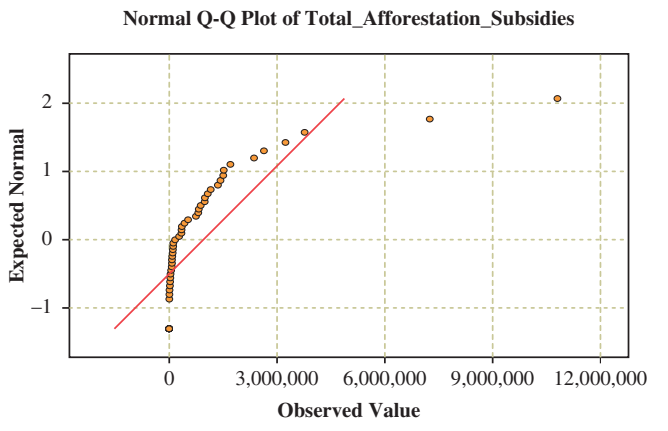

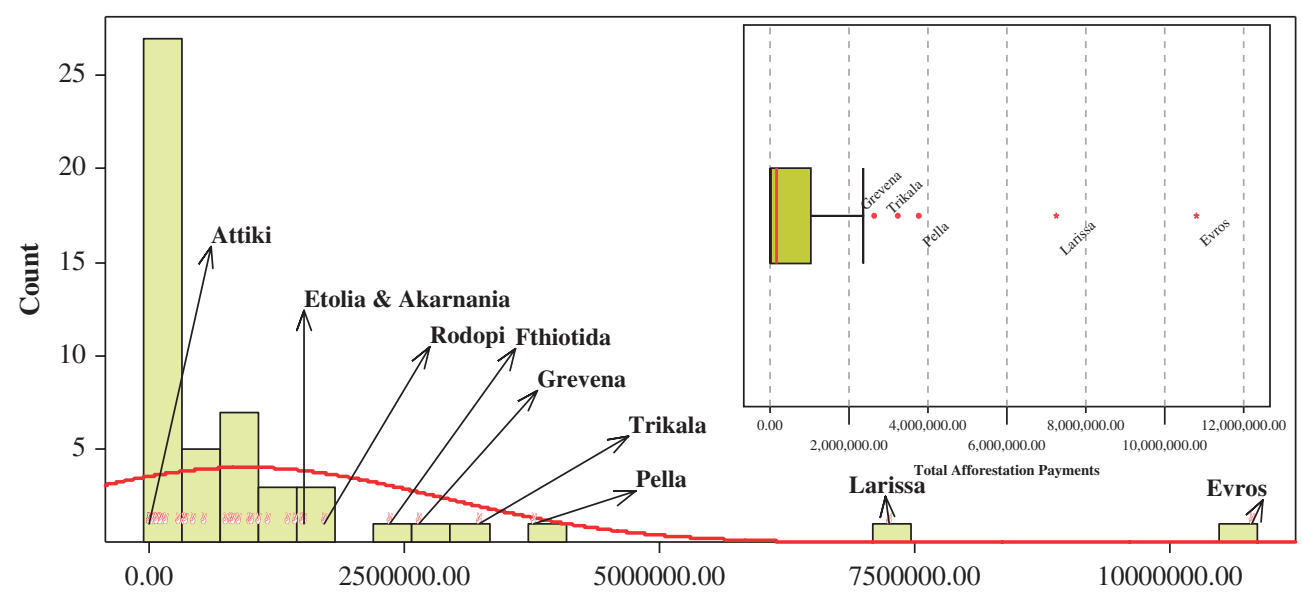

Figure 3: Stem and leaf plot, normal probability Q-Q plot, histogram and box plot of the dependent variable.

Policy programmes. The variable represents the mean gross domestic product of each prefecture in agriculture to the mean gross national product (GNP) in agriculture for the period from 1991 to 1998 in a prefectural level. It has been estimated by using the following formula:

$$
\frac{A G R_{i} \_ \text {mean_GDP }}{A G R_{-} \text {mean_GNP }}
$$

where $A G R_{i-}$ mean_GDP is the mean gross domestic product in agricultural sector in the prefecture $i$ for the period from 1991 to 1998 and AGR_mean_GDP is the mean GNP in agriculture for the same period.

- Average land plot size: Agricultural land plots vary in size as well as the extent to which they are serviced with infrastructure. As agricultural production takes place in space, the size of land plots is of critical importance, in that agricultural operations in sizable land plots generated economies of scale thereby lowering the cost of production. Therefore, we expect that the prefecture with large average land plot size will be less likely to change their use of land through afforestation programmes.

- Level of prosperity in each prefecture: We believe that higher standards of living in a prefecture are associated with more productive activities of all sectors as well as more productive agricultural 
holdings and operations. Therefore, we expect that the prefectures with high prosperity levels will be less kin on changing their use of land to forest land. The prosperity level is a synthetic indicator deriving from the relative share of each prefecture to the formation of GNP as well as the levels of regional consumption and civil infrastructure. The data concerning this variable come from a study by Petrakos and Polyzos [9].

- Change in urban population: The urban population variable represents the percent change of a prefecture's population defined as urban. We calculate change scores with point estimates for 1991 and 2001 obtained by the National Statistical Service of Greece (NSSG). Dynamics relating urban population changes and participation in afforestation activities are complex. Rural to urban migration movements might result in the abandonment of marginal agricultural land and hence in natural reforestation, but less scope for afforestation. The rate of urbanisation, therefore, could reduce the size of the agricultural rural population and the level of participation in afforestation activities.

- Row crop areas to agricultural tree areas: This variable represents the ratio of the total area of row-crop-based agricultural systems in each prefecture to the total area of tree-based agricultural systems. Tree-based agricultural land uses are usually considered as more permanent in relation to row crop systems. The row crop system centres around the cultivation of a variety of food crops and cash crops such as cotton. However, inadequate access to water which is often limited in quantity and of poor quality as well as low market competitiveness for Greek agricultural produce have put considerable pressure on row crop areas. We think that the prefectures with high ratio of row crop areas to agricultural tree areas are more likely to participate in afforestation projects taking advantage of the fiscal incentives.

- Ratio of the number of agricultural businesses to the generated revenues: The ratio of the number of agricultural businesses in each prefecture to the generated revenue in the primary sector is a representative indicator of the size, strength and productivity of the regional primary sector. Economically speaking, when the ratio is low, agricultural businesses have larger sizes, are more capital than labour intensive and they are also more competitive. We expect that the prefectures with low values of this indicator are less likely to get involved in afforestation projects.

- Informal housing activity: Recently, the informal housing phenomenon has attracted much attention and has been approached through the concept of 'syndromes of global change'. It is considered as a major proximate cause of land use change and has been named as the 'Favela syndrome'. However, 'Favela syndrome' refers mainly to uncontrolled and unsustainable urbanisation processes in developing countries. Informal settlements in Greece form a complex issue. These groups of housing units are associated with a diverse population of a wide variety of social and economic backgrounds. The phenomenon is taking up large areas of both marginal and productive agricultural land as well as forest land. Spatially speaking, we expect that if there is an association between participation in afforestation projects and informal housing activity, it will be negative because of the antagonism for land between the two processes. Data for this variable come from the relevant annual building activity tables published by NSSG [10].

- Geographical zone: Differentiations in geographical characteristics and climatic conditions between the Greek prefectures are great. The introduction of this variable into the analysis was intended to uncover any likely relationship between participation in afforestation and the geographical location of prefectures. In particular, there is a well-defined scaling along as well as across the Greek peninsula regarding climatic conditions. In the north and west parts of the country, the precipitation patterns result in increased rainfall and snow or sleet conditions, whereas moving to the east and south climatic conditions become milder. For the purpose of the present analysis, three geographical zones were formed: the north zone, the central zone and the south zone. Data for this variable come from NSSG [11]. 
A summary of the above variables and their data sources are presented in Table 3.

\subsection{Methodology}

The provision of update information for improving regulatory, planning and design activities requires that any policy appraisal efforts focus on assessing and uncovering the likely factors that influence the policy's performance. Among the methodologies employed to accomplish this task are several types of regression models which sustain certain advantages and limitations. A rather large array of models and techniques has developed in order to capture, analyse, explain and forecast complex spatial processes and phenomena such as afforestation participation patterns. Depending on the research question, the nature of data concerning the response and the explanatory variables (continuous, ordinal, binary, interval, ratio) as well as likely relationships between explanatory variables, it may

Table 3: Summary of variables and data sources.

\begin{tabular}{|c|c|c|c|}
\hline Variable & Description & $\begin{array}{l}\text { Category/scale } \\
\text { of measurement }\end{array}$ & Data sources \\
\hline $\begin{array}{l}\text { Afforestation } \\
\text { payments }\end{array}$ & $\begin{array}{l}\text { Total afforestation payments per } \\
\text { prefecture for the period 2002-2005 }\end{array}$ & $\begin{array}{l}\text { Policy factor/ratio } \\
\text { transformed into } \\
\text { ordinal }\end{array}$ & $\begin{array}{l}\text { Ministry of Rural } \\
\text { Development } \\
\text { and Food }\end{array}$ \\
\hline $\begin{array}{l}\text { Specialisation in } \\
\text { the primary sector }\end{array}$ & $\begin{array}{l}\text { The share of the primary sector } \\
\text { of the economy in the total } \\
\text { production in each prefecture }\end{array}$ & $\begin{array}{l}\text { Economic } \\
\text { factor/ratio }\end{array}$ & $\begin{array}{l}\text { NSSG [10]; } \\
\text { Epilogi [12] }\end{array}$ \\
\hline $\begin{array}{l}\text { Average land plot } \\
\text { size }\end{array}$ & $\begin{array}{l}\text { Mean size of agricultural holding in } \\
\text { each prefecture }\end{array}$ & $\begin{array}{l}\text { Economic } \\
\text { factor/ratio }\end{array}$ & NSSG [11] \\
\hline $\begin{array}{l}\text { Level of prosperity } \\
\text { in each prefecture }\end{array}$ & $\begin{array}{l}\text { The contribution of each prefecture } \\
\text { to the GNP of Greece and to GNP } \\
\text { per capita in euro as well as in } \\
\text { Purchasing Power Standards }\end{array}$ & $\begin{array}{l}\text { Economic } \\
\text { factor/interval }\end{array}$ & $\begin{array}{l}\text { Petrakos and } \\
\text { Polyzos [9] }\end{array}$ \\
\hline $\begin{array}{l}\text { Change in urban } \\
\text { population }\end{array}$ & $\begin{array}{l}\text { Rural population in } 2001 \text { to rural } \\
\text { population in } 1991\end{array}$ & $\begin{array}{l}\text { Demographic } \\
\text { factor/ratio }\end{array}$ & NSSG [8] \\
\hline $\begin{array}{l}\text { Ratio of areas of } \\
\text { agricultural row } \\
\text { crops to areas of } \\
\text { agricultural trees }\end{array}$ & $\begin{array}{l}\text { Ratio of areas of agricultural row } \\
\text { crops to areas of agricultural trees }\end{array}$ & $\begin{array}{l}\text { Economic } \\
\text { factor/ratio }\end{array}$ & NSSG [11] \\
\hline $\begin{array}{l}\text { Number of } \\
\text { agricultural } \\
\text { businesses to the } \\
\text { generated revenues }\end{array}$ & $\begin{array}{l}\text { The ratio of the number of } \\
\text { agricultural businesses in each } \\
\text { prefecture to the generated revenue } \\
\text { in the primary sector }\end{array}$ & $\begin{array}{l}\text { Economic } \\
\text { factor/ratio }\end{array}$ & NSSG [11] \\
\hline $\begin{array}{l}\text { Informal housing } \\
\text { activity }\end{array}$ & $\begin{array}{l}\text { Number of informal housing units } \\
\text { per } 1,000 \text { residents that entered into } \\
\text { the legalisation process during the } \\
\text { period from } 1997 \text { to } 2006\end{array}$ & $\begin{array}{l}\text { Economic } \\
\text { factor/ratio }\end{array}$ & NSSG [10] \\
\hline Geographical zone & $\begin{array}{l}\text { Three climatic zones according to } \\
\text { the Greek Presidential Decree } \\
352 / 1979\end{array}$ & $\begin{array}{l}\text { Physical } \\
\text { factor/ordinal }\end{array}$ & $\begin{array}{l}\text { Greek Presidential } \\
\text { Decree } \\
352 / 1979\end{array}$ \\
\hline
\end{tabular}


be appropriate to consider other types of regression analysis than the linear model [13]. A frequently used statistical method in land use studies is multiple logistic regression analysis. Logistic regression is part of a category of statistical models called generalised linear models. The multinomial logistic regression technique is an extension of the binomial logistic model to the cases where the response variable has more than two categories [14] (e.g. not just not receiving afforestation payments and receiving afforestation payment but low afforestation payments, medium afforestation payments, high afforestation payments, etc.). In this case, the response variable of interest exhibits a multinomial distribution and not a binomial as in a simple logistic model. This type of regression does not assume that the relationships between the explanatory variables and the dependent variable are linear. Furthermore, it does not assume that the response variable and the error terms are distributed normally. Finally, it allows one to predict a discrete outcome, such as group membership, from a set of variables that may be continuous, discrete, dichotomous or a mix of any of these.

As discussed earlier, the distribution of the continuous variable 'level of regional payments through afforestation projects' does not fit the normal distribution. Having transformed it into a categorical one with three categories, we can investigate possible relationships with both continuous and discrete explanatory variables. We set the medium category afforestation payments as the reference category and formed two non-redundant logits. Using the general formula of logistic regression (eqns (2) and (3)), we constructed logit A (eqn (4)) and logit B (eqn (5)):

$$
\operatorname{prob}(Y=j)=\frac{\exp \left(a_{0 j}+\beta_{1 j} X_{1}+\beta_{2 j} X_{2}+\cdots+\beta_{n j} X_{n}\right)}{\sum_{i=1}^{m} \exp \left(a+\beta_{1 i} X_{1}+\beta_{2 i} X_{2}+\cdots+\beta_{n j} X_{n}\right)}
$$

or

$$
\ln \left[\frac{\operatorname{prob}_{(i \text {-category })}}{\operatorname{prob}_{(j \text {-category })}}\right]=\alpha_{0 i}+\beta_{1 i} X_{1}+\beta_{2 i} X_{2}+\cdots+\beta_{n i} X_{n}+\varepsilon_{i}
$$

where $\operatorname{prob}_{(i \text {-category })}$ is the likelihood of the dependent variable being in the $i$ category, $i=1, \ldots, m$ is the number of categories; prob $_{(j \text {-category })}$ is the likelihood of the dependent variable being in the $j$ category (the baseline category); $X_{n}$ are the explanatory variables $1, \ldots, n$, employed by the empirical model; $\alpha_{0 i}$ is the intercept for logit $i ; \beta_{n i}$ are the regression coefficients of the $n$ variables for logit $i$; $\varepsilon_{i}$ are the residuals for logit $i$.

In the case of the afforestation empirical model, the two logits which we create have the following form:

$$
\begin{aligned}
\text { Logit_A } & =\ln \left[\frac{\text { prob(afforestation }=\text { no_or_low })}{\text { prob }(\text { afforestation }=\text { medium })}\right] \\
& =b_{0 A}+b_{1 A} X_{1}+b_{2 A} X_{2}+\cdots+b_{n A} X_{n}+\varepsilon_{i}
\end{aligned}
$$


Logit A shows the log of the odds of the probability that a prefecture is in the 'no or low afforestation' category than in the medium afforestation category. In turn, logit B depicts the log of the odds of the probability of a prefecture being in the 'high afforestation' category than in the medium afforestation category. In the following section, we calculate the parameter estimates as well as some model fitting statistics.

\section{RESULTS AND DISCUSSION}

\subsection{Model fitting information}

In our initial classification of spatial units in relation to the afforestation payments that they received during the study period, we assigned 22 prefectures in the first category, 16 prefectures in the second category and 13 prefectures in the third category. The classification table (Table 4) shows that the model classifies correctly all 22 prefectures of the first category. In the second category, there are only two incorrect classifications leaving the correct ones at 14. Finally, in the last category, $84.6 \%$ of the cases are classified correctly. In total, $92.2 \%$ of the cases are assigned correctly. This means that the classification performance of the model is very high.

We use the likelihood ratio test (LRT) to test the hypothesis that all coefficients in the final model are 0 . In doing so, we compare the $-2 \log$-likelihood for an intercept-only model with our final model. From the observed significance level, we can reject the null hypothesis of zero coefficients. As regards the pseudo $R^{2}$ measures, all of them are relatively large indicating that a great part of the variation is explained by the current model (Table 5).

Table 4: Classification.

\begin{tabular}{lcccc}
\hline Observed & \multicolumn{4}{c}{ Predicted } \\
\cline { 2 - 5 } & 1 & 2 & 3 & Percent correct \\
\hline 1 & 22 & 0 & 0 & 100.0 \\
2 & 0 & 14 & 2 & 87.5 \\
3 & 0 & 2 & 11 & 84.6 \\
Overall percentage & 43.1 & 31.4 & 25.5 & 92.2 \\
\hline
\end{tabular}

Table 5: Model fitting information and pseudo $\mathrm{R}^{2}$.

\begin{tabular}{|c|c|c|c|c|}
\hline \multirow[t]{2}{*}{ Model } & \multirow{2}{*}{$\begin{array}{l}\text { Model fitting criteria } \\
\text {-2Log likelihood }\end{array}$} & \multicolumn{3}{|c|}{ Likelihood ratio tests } \\
\hline & & $\chi^{2}$ & d.f. & Significance \\
\hline Intercept only & 109.629 & & & \\
\hline Final & 31.785 & 77.843 & 20 & 0.000 \\
\hline Pseudo $R^{2}$ & & & & \\
\hline Cox and Snell & & & & 0.783 \\
\hline Nagelkerke & & & & 0.886 \\
\hline McFadden & & & & 0.710 \\
\hline
\end{tabular}


Table 6: Likelihood ratio tests.

\begin{tabular}{|c|c|c|c|c|}
\hline \multirow[t]{2}{*}{ Effect } & \multirow{2}{*}{ 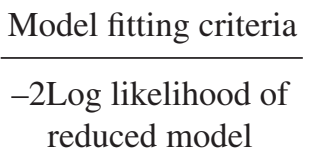 } & \multicolumn{3}{|c|}{ Likelihood ratio tests } \\
\hline & & $\chi^{2 *}$ & d.f. & Significance \\
\hline Intercept & $31.785^{\mathrm{a}}$ & 0.000 & 0 & \\
\hline $\begin{array}{l}\text { Specialisation in the } \\
\text { primary sector }\end{array}$ & 53.465 & 21.680 & 2 & 0.000 \\
\hline Average land plot area & 46.795 & 15.010 & 2 & 0.001 \\
\hline Prosperity level & 38.890 & 7.105 & 2 & 0.029 \\
\hline Rate of urban population & 43.352 & 11.566 & 2 & 0.003 \\
\hline $\begin{array}{l}\text { Ratio of areas of } \\
\text { agricultural row crops to } \\
\text { areas of agricultural trees }\end{array}$ & 38.994 & 7.208 & 2 & 0.027 \\
\hline $\begin{array}{l}\text { Ratio of number of } \\
\text { agricultural businesses } \\
\text { to generated revenues }\end{array}$ & 55.662 & 23.877 & 4 & 0.000 \\
\hline $\begin{array}{l}\text { Informal housing per } \\
1,000 \text { people }\end{array}$ & 41.602 & 9.816 & 2 & 0.007 \\
\hline Geographical zone & 70.716 & 38.931 & 4 & 0.000 \\
\hline
\end{tabular}

*The $\chi^{2}$ statistic is the difference in $-2 \log$ likelihoods between the final model and a reduced model. The reduced model is formed by omitting an effect from the final model. The null hypothesis is that all parameters of that effect are 0 .

${ }^{a}$ This reduced model is equivalent to the final model because omitting the effect does not increase the d.f.

The LRT present in Table 6 is a statistical test of the goodness-of-fit between two models. A relatively more complex model is compared to a simpler. In this case, we compare the effect of each independent variable to the dependent variable by comparing a model which includes the variable and a model without the variable. As we can see, the significance levels of all independent variables are very low implying that they contribute to the model.

\subsection{Parameter estimates}

The results of the empirical analysis are presented in Table 7. The interpretation of the results concerning both logits is formulated according to the following rules:

- Level of significance lower than 0.05 indicates that the $95 \%$ confidence interval for $\operatorname{Exp}(\mathrm{B})$ does not include 0 .

- Explanatory variables with negative coefficients decrease the likelihood of the response category in the logit they refer to, in relation to the baseline category.

- Explanatory variables with positive coefficients increase the likelihood of the response category in the logit they refer to, in relation to the baseline category.

As regards logit $\mathrm{A}$, the covariates that are significantly different from 0 are specialisation in the primary sector, prosperity level, rate of urban population and ratio of agricultural row crops to 
Table 7: Parameter estimates.

\begin{tabular}{|c|c|c|c|c|c|}
\hline Agricultural land use change ${ }^{a}$ & $\mathrm{~B}$ & $\begin{array}{l}\text { Standard } \\
\text { error }\end{array}$ & $\begin{array}{l}\text { Wald } \\
\text { statistic }\end{array}$ & Significance & $\operatorname{Exp}(B)$ \\
\hline \multicolumn{6}{|l|}{ Logit A } \\
\hline Intercept & 44.442 & 26.697 & 2.771 & 0.096 & \\
\hline $\begin{array}{l}\text { Specialisation in the primary } \\
\text { sector }\end{array}$ & -1.138 & 0.512 & 4.935 & 0.026 & 0.320 \\
\hline Average land plot area & -1.315 & 1.224 & 1.154 & 0.283 & 0.268 \\
\hline Prosperity level & 0.609 & 0.359 & 2.878 & 0.090 & 1.839 \\
\hline Rate of urban population & -0.299 & 0.164 & 3.308 & 0.069 & 0.741 \\
\hline $\begin{array}{l}\text { Ratio of agricultural row } \\
\text { crops to agricultural trees }\end{array}$ & 0.436 & 0.239 & 3.349 & 0.067 & 1.547 \\
\hline \multicolumn{6}{|l|}{$\begin{array}{l}\text { Ratio of number of } \\
\text { agricultural businesses to } \\
\text { generated revenues }\end{array}$} \\
\hline$[1]$ & -5.463 & 3.495 & 2.444 & 0.118 & 0.004 \\
\hline$[2]$ & 5.305 & 2.978 & 3.173 & 0.075 & 201.349 \\
\hline$[3]$ & $0^{\mathrm{b}}$ & & & & \\
\hline \multicolumn{6}{|l|}{$\begin{array}{l}\text { Informal housing per } \\
1,000 \text { people }\end{array}$} \\
\hline $\begin{array}{l}{[1]} \\
{[2]}\end{array}$ & $\begin{array}{c}-10.028 \\
0^{b}\end{array}$ & 5.388 & 3.463 & 0.063 & $4.42 \mathrm{E}-005$ \\
\hline \multicolumn{6}{|l|}{ Geographical zone } \\
\hline [1] & -42.712 & 19.805 & 4.651 & 0.031 & $2.82 \mathrm{E}-019$ \\
\hline$[2]$ & -5.768 & 3.631 & 2.523 & 0.112 & 0.003 \\
\hline$[3]$ & $0^{\mathrm{b}}$ & & & & \\
\hline \multicolumn{6}{|l|}{ Logit B } \\
\hline Intercept & 5.944 & 7.447 & 0.637 & 0.425 & \\
\hline $\begin{array}{l}\text { Specialisation in the primary } \\
\text { sector }\end{array}$ & -0.131 & 0.087 & 2.236 & 0.135 & 0.878 \\
\hline Average land plot area & 1.507 & 0.649 & 5.381 & 0.020 & 4.511 \\
\hline Prosperity level & -0.175 & 0.174 & 1.006 & 0.316 & 0.840 \\
\hline Rate of urban population & -0.276 & 0.120 & 5.243 & 0.022 & 0.759 \\
\hline $\begin{array}{l}\text { Ratio of agricultural row } \\
\text { crops to agricultural trees }\end{array}$ & 0.016 & 0.030 & 0.283 & 0.595 & 1.016 \\
\hline \multicolumn{6}{|l|}{$\begin{array}{l}\text { Ratio of number of } \\
\text { agricultural businesses to } \\
\text { generated revenues }\end{array}$} \\
\hline$[1]$ & 12.948 & 5.104 & 6.436 & 0.011 & $419,933.444$ \\
\hline$[2]$ & 12.815 & 4.988 & 6.602 & 0.010 & $367,845.97$ \\
\hline$[3]$ & $0^{\mathrm{b}}$ & & & & \\
\hline
\end{tabular}


Table 7: Continued

\begin{tabular}{lccccc}
\hline Agricultural land use change $^{\mathrm{a}}$ & $\mathrm{B}$ & $\begin{array}{c}\text { Standard } \\
\text { error }\end{array}$ & $\begin{array}{c}\text { Wald } \\
\text { statistic }\end{array}$ & Significance & Exp(B) \\
\hline $\begin{array}{l}\text { Informal housing per } \\
\text { 1,000 people }\end{array} \quad$ [1] & & & & & \\
$\quad$ [2] & -0.969 & 1.494 & 0.420 & 0.517 & 0.380 \\
$\begin{array}{l}\text { Geographical zone } \\
\quad 0^{\mathrm{b}}\end{array}$ & & & & \\
$\quad[2]$ & -9.715 & 4.938 & 3.870 & 0.049 & $6.04 \mathrm{E}-005$ \\
$\quad[3]$ & -14.978 & 6.522 & 5.273 & 0.022 & $3.13 \mathrm{E}-007$ \\
\hline
\end{tabular}

${ }^{a}$ The reference category is $100,000.01-1,000,000.00$.

${ }^{\mathrm{b}}$ This parameter is set to zero because it is redundant.

agricultural trees. There are also some factor variables which contribute to the separation of the prefecture between low afforestation areas and medium afforestation areas. These are the ratio of the number of agricultural businesses to the generated revenues when it takes medium values, the informal housing per 1,000 people when it takes low values and the geographical zone when the prefecture belong to the first zone.

The relational patterns are somewhat different in logit B. Significantly different from 0 are the coefficients of average land plot area and rate of urban population for covariates and ratio of number of agricultural businesses to generated revenues and geographical zone for factor variables.

As regards the first variable, the coefficients are negative for both logits but significantly different from 0 only for logit A. This indicates that the prefectures with low specialisation in the primary sector are less likely to participate in afforestation projects than the ones with increased specialisation in this sector. However, the specialisation in the primary sector is not significantly related to the separation between medium and high participation in afforestation project. Hence, although a certain level of specialisation of the local economy in the primary sector is required in order for a prefecture to get involved in afforestation projects, the actual level of involvement is not determined by the degree of specialisation. The negative sign in logit B, although not statistically significant, implies that prefectures with very high specialisation in the primary sector maybe reluctant to increase their involvement in afforestation projects. These results seem logical if we consider that (a) demand for participating in afforestation projects requires that there is some minimum agricultural activity in place and (b) that this activity is not profitable enough to discourage individual farmers from seeking alternative, more profitable uses for their land. In highly specialised prefectures where the patterns of agricultural production generate important revenues, there might be less scope for participation in afforestation projects. A likely reason is that these areas are extensive production areas and the individuals participate only in those areas that are less productive.

Coming into the variable of average land plot size, we can see that for the first logit the coefficient is negative but not statistically significant, whereas for the second logit the coefficient is positive and statistically significant. These results are not consistent with our initial expectations. We expected that the prefectures with large average land plot size would have been less likely to change their use of land through afforestation programmes due to economies of scale in production. However, the results for logit B indicate that the level of participation in afforestation projects is analogous to land 
plot size. A possible explanation for these results is that, in economic grounds, land plots of small size are not worth assigning in afforestation projects. Generating revenues of some importance requires converting sizable areas of marginal agricultural land to forests. This might be the case in most insular prefectures where the average size of land plots is low and the participation in afforestation projects is minimal. Even if the land is marginal, it seems that locations with low average land plot size are less likely to get involved in afforestation activities. When designing a policy, this should be taken in account if it is to improve forest resources of areas with low forest cover like the coastal and insular prefectures.

The level of prosperity in each prefecture appears to be statistically significant and positively related with low levels of participation in afforestation projects. This indicates that as the regional level of prosperity increases, the likelihood of getting involved in afforestation projects decreases. This is logical because in prosperous regions there are usually more alternative land uses for a landowner to consider which are also much more profitable than the afforestation choice. Although the sign of the coefficient of this variable for logit B is logical, meaning that high prosperity levels lower the likelihood of a prefecture to be interesting in establishing extensive afforested areas, the level of statistical significance is not satisfactory.

The rate of urban population appears negative and statistically significant for both logits. These results create a very complex pattern of relation which schematically looks like Fig. 4.

The signs indicate that neither very high nor very low participation in afforestation projects is favoured by urbanisation. By running a curve estimation procedure for the two variables, it appears that there might be an S-shaped relationship (the level of statistical significance in the curve estimation

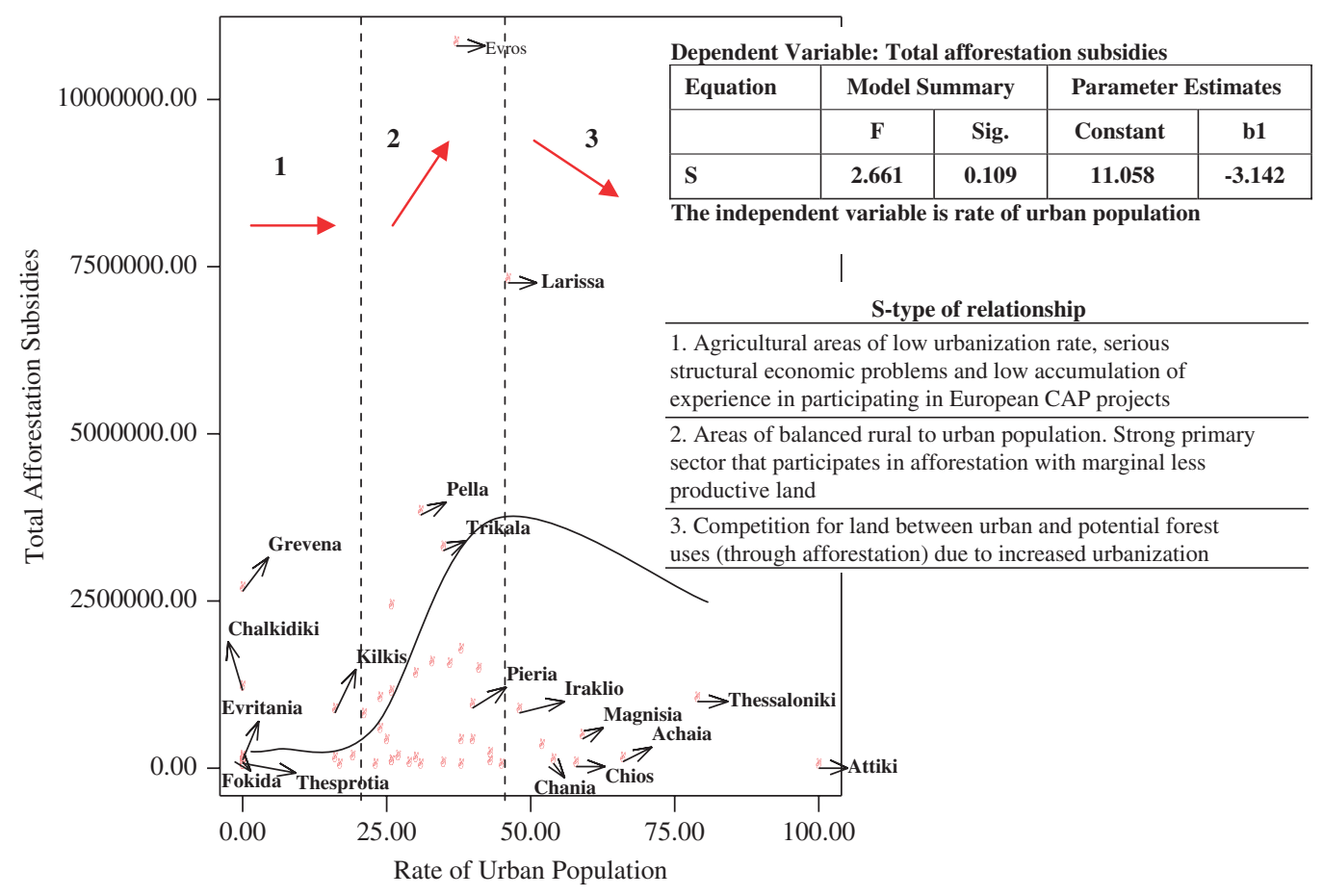

Figure 4: Further analysis of the relational pattern between total afforestation subsidies and rate of urban population. 
procedure is 0.109 which is very close to 0.1 ). It seems that urbanisation is associated with medium levels of afforestation. As regards logit B, it can be said that the direction of the relation is logical. Increased urbanisation requires new land for development, and therefore, there is less scope for afforestation due to antagonistic dynamics between potential forest land uses and urban uses. A possible explanation for the relation in logit A, namely that increased urbanisation does not favour very low afforestation, may be that the prefectures of low urbanisation rates have serious structural economic problems, negative demographic indicators, limited administrative capacity and low accumulation of experience in participating in European CAP projects.

The coefficient of the ratio of agricultural row crops to agricultural trees is positive and statistically significant with a $p$-value of 0.067 for logit A and positive but not statistically significant for logit B. These results indicate that the prefectures with high ratio of row crop areas to agricultural tree areas are less likely to participate in afforestation projects, something which is against our initial expectations. A likely explanation for these results is that despite the considerable pressure on row crops due to intense competition at the international trade level, they still generate important revenues for farmers not least due to CAP subsidies. Therefore, subsidisation of certain row crops could be a possible reason for landowners resisting the planting of land with trees.

As was mentioned earlier, the ratio of the number of agricultural businesses in each prefecture to the generated revenue in the primary sector is an indicator of the size, strength and productivity of the regional agricultural businesses. According to the values of the ratio, the variable was transformed into a categorical one. The first category of the variable represents the prefectures in which the majority of businesses are of large size and increased productivity, the second category represents the prefectures in which most of the agricultural companies have medium sizes and the last category was assigned to the prefectures of small, less productive businesses. For the first logit, the coefficient for category 1 is negative but not statistically significant, whereas for the second category the coefficient is positive and statistically significant. This means that the prefectures with medium size agricultural businesses are more likely to choose not to participate in afforestation schemes compared to the prefectures of small, less productive agricultural businesses. Financially speaking, this is logical because as the productivity and profits of an agricultural business get improved, the business is becoming more reluctant in changing the use of its land. Coming to the second logit, we see that the coefficients for both the first and second categories of the variable are positive and statistically significant. These results seem odd as they suggest that the prefectures with the large and medium size, productive agricultural companies are more likely to participate in afforestation schemes at a high and not a medium level compared to the prefectures with small, less productive businesses. However, a possible explanation for these results is that the prefectures with large, productive businesses are more organised in economic and administrative grounds, more experienced in dealing with opportunities and incentives deriving from CAP regulations and therefore, they have the ability of taking advantage of afforestation schemes by assigning their less productive land to tree planting. On the other hand, the less productive prefectures usually experience serious structural problems in the primary sector, have low administrative capacity and limited experience in dealing with agricultural policy initiatives and therefore they are almost incapable of taking advantage of schemes that are of particular importance to them.

As regards informal housing, we can see that the parameter estimate is not significantly different from 0 for the second logit but is significantly different for the first logit. This indicates that informal housing is not significantly related to the separation of the high afforestation and medium afforestation groups but that it is useful in separating the low afforestation and medium afforestation groups of prefectures. The negative sign of the coefficient indicates that the prefectures with low informal housing activity are less likely to choose low participation in afforestation schemes compared to the prefectures with high 
informal housing activity. There appears to be a relationship between participation in afforestation schemes and informal housing activity. In the prefectures in which informal housing activity is high, afforestation schemes struggle to be put into operation possibly due to the antagonistic character of the processes.

Finally, differentiations in geographical characteristics and climatic conditions seem to have played a role in the level of participation in the afforestation schemes. However, the generated pattern is a very complex one. For the first logit, the coefficient for geographical zone 1 is negative and statistically significant indicating that the north and mountainous part of the country are less likely not to participate in afforestation schemes compared to the south coastal and insular part of the country. Climatic conditions and water resources favour at least some medium participation in afforestation schemes.

For the second logit, both coefficients for zones 1 and 2 are negative and statistically significant. This is odd, as we would expect positive signs for these two zones. The results indicate that being in the geographical zones 1 and 2 does not necessarily mean very high participation in afforestation schemes. There are many prefectures in these zones that had a lower performance in terms of afforestation compared to the prefectures of zone 3 as we can see in the box plot of Fig. 5. However, this issue needs further investigation in order to draw safer conclusions.

Figure 6 provides an overview and summary of the major influential factors regarding the implementation of EU afforestation policy in Greece through the Council Regulations 2080/92 and $1257 / 1999$.

\section{CONCLUSIONS}

Within EU agricultural policy makers, it is increasingly accepted that the CAP afforestation programmes have not met initial expectations and that most of the goals set have not yet been fulfilled as the areas planted with trees are far less than the expected ones. This is clearly stressed in the MEACAP Working Paper 4 on Impacts of Environmental Agreements on the CAP which reports that the potential role of afforestation in agricultural areas was considerably over-estimated in the 1980s, as environmental, economic, social and legal constraints were not taken into account. It seems that several

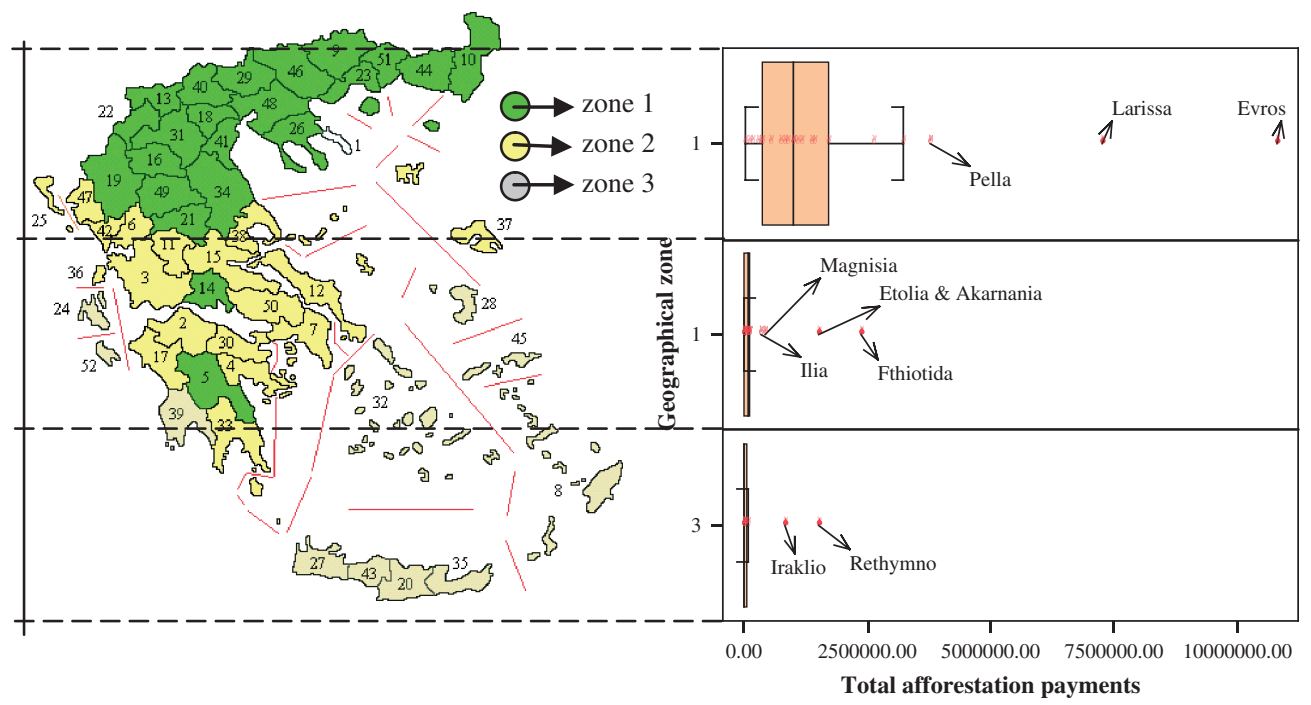

Figure 5: Map of geographical zones according to climatic conditions and topographical characteristics and box plot of total afforestation payments in each geographical zone. 


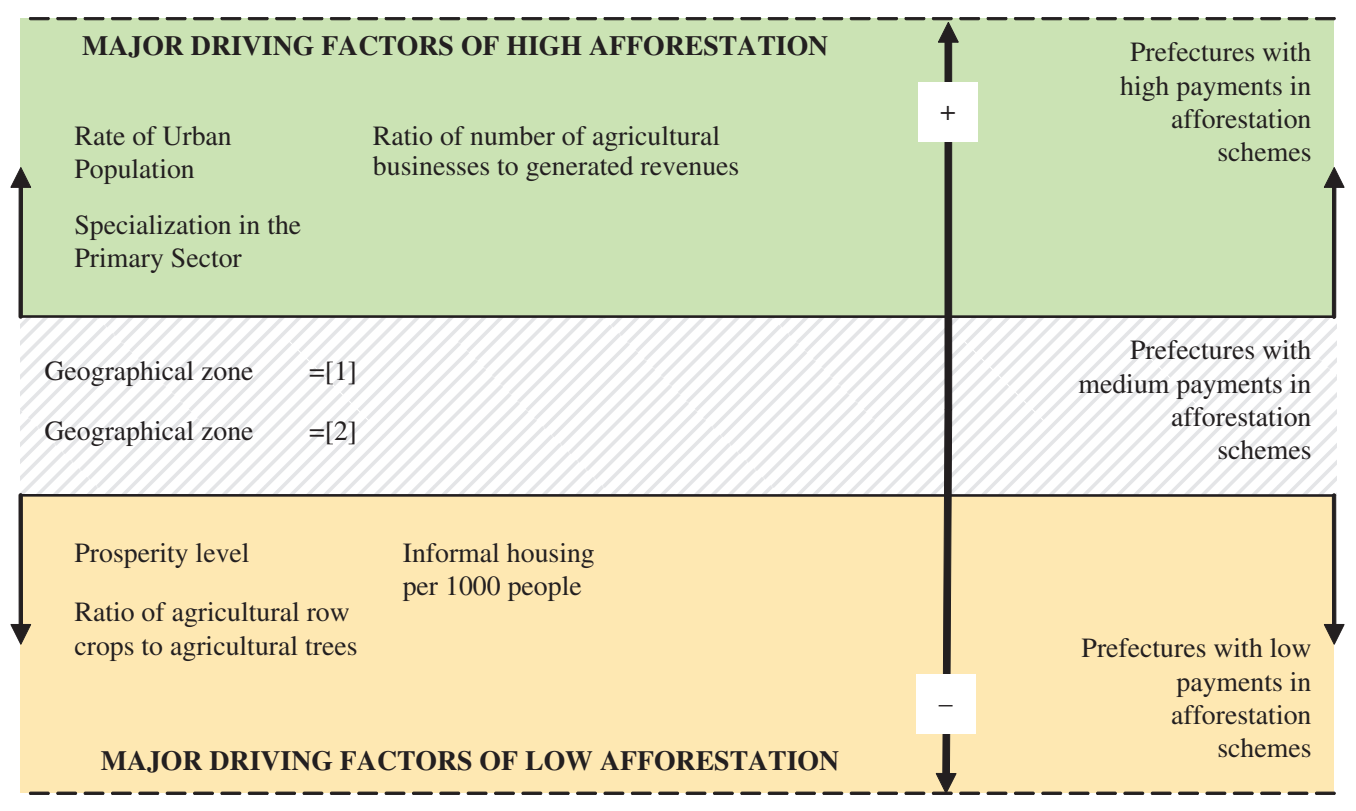

Figure 6: Overview of logistic regression results on the major influential factors regarding the implementation of EU afforestation policy in Greece.

countries perform better than others and that the areas with a real need to increase their forest land (e.g. several Mediterranean areas) have not managed to take full advantage of this policy initiative.

Variations within countries are also important. Spatially speaking, the participation in afforestation schemes and therefore the economic, social and environmental implications of afforestation regulations 2080/92 and 1257/99 of the EU have not been evenly distributed among the Greek prefectures. Prefectures with distinctive differences in their social and economic structure as well as their natural characteristics have responded differently to the regulations. Therefore, the general performance of an agro-ecological policy such as afforestation policy would possibly benefit and become more effective if supplemented by spatially specific information combined with a thorough understanding of the policy context for activities promoting land conversion to forest. This requires uncovering the major regional characteristics that have a real influence on policy success. The present empirical research has shown that an amalgam of factors can influence policy implementation measures.

Factors like the degree of specialisation of the local economy in the primary sector, the regional prosperity level, the level of urbanisation and the orientation of cultivated areas either to tree or row crops are significant issues to consider in order to improve policy effectiveness. The size and productivity of local agricultural businesses and general climatic and topographic conditions should also be taken into account. Finally, country- or region-specific processes such as informal housing or urban sprawl may increase the competition for land having a negative influence on afforestation policies. Therefore, evaluating policy results and uncovering the likely factors that act in favour or against afforestation efforts could be a major step in designing and applying more effective and successful forest measures. In this way, afforestation programmes would have an important role in protecting and improving biodiversity, mitigating climate change through carbon sequestration, providing plant biomass for fossil fuel substitution as well as helping local communities against natural disasters such as soil erosion and flooding. 


\section{REFERENCES}

[1] Buttoud, G., Forest policy evaluation in Europe: state of art. Forest Policy and Economics, 8(5), pp. 499-501, 2006. doi:10.1016/j.forpol.2005.07.001

[2] Croitoru, L., How much are Mediterranean forests worth? Forest Policy and Economics, 9(5), pp. 536-545, 2007. doi:10.1016/j.forpol.2006.04.001

[3] Arabatzis, G. \& Christopoulou, O., Afforestation of agricultural land as a measure of management and development of rural areas. Sustainable World, Vol. 6, eds E. Beriatos, C.A. Brebbia, H. Coccossis et al., Skiathos Island, 2003.

[4] Kassioumis, K., Papageorgiou, K., Christodoulou, A. et al., Rural development by afforestation in predominantly agricultural areas: issues and challenges from two areas in Greece. Forest Policy and Economics, 6(5), pp. 483-496, 2004. doi:10.1016/S1389-9341(02)00079-5

[5] Madsen, L.M., New woodlands in Denmark: the role of private landowners. Urban Forestry and Urban Greening, 1(3), pp. 185-195, 2003. doi:10.1078/1618-8667-00018

[6] Santos, T., Telleria, J.L., Diaz, M. et al., Evaluating the benefits of CAP reforms: can afforestations restore bird diversity in Mediterranean Spain? Basic and Applied Ecology, 7(6), pp. 483-495, 2006. doi:10.1016/j.baae.2005.11.001

[7] European Union, Assessment of the Application of Regulation (EEC) No 2080/92 on the measures of afforestation in the agricultural sector, Luxembourg, EU, 1997.

[8] NSSG, Statistical Yearbook of Greece, Athens, Hellenic Republic, 2004.

[9] Petrakos, G. \& Polyzos, S., Regional inequalities in Greece: literature review and estimations of inequalities. Studies in Greek Economy, Vol. 1, eds M. Chletsos, C. Kollias \& H. Naxakis, Patakis: Athens, 2005.

[10] NSSG, Yearly Data on Construction Activity in Greece, Pireas, Hellenic Republic, 2005.

[11] NSSG, The Structure of Agricultural Holdings, Pireas, Hellinic Rebuplic, 2003.

[12] Epilogi, The Greek Prefectures, Athens, 1998.

[13] Norusis, M., SPSS 13.0 Advanced Statistical Procedure Companion, Prentice Hall: New Jersey, 2004.

[14] Norusis, M., SPSS 14.0 Statistical Procedures Companion, Prentice Hall Inc.: New Jersey, 2005. 